\title{
miR-146a promotes cervical cancer cell viability via targeting IRAK1 and TRAF6
}

\author{
QIMING HU $^{1 *}$, JIACHENG SONG $^{2 *}$, BO DING $^{3}$, YUGUI CUI $^{1}$, JIALE LIANG $^{1}$ and SUPING HAN ${ }^{1}$ \\ Departments of ${ }^{1}$ Obstetrics and Gynecology and ${ }^{2}$ Radiology, The First Affiliated Hospital of \\ Nanjing Medical University, Nanjing, Jiangsu 210036; ${ }^{3}$ Department of Obstetrics and Gynecology, \\ Zhongda Hospital, Medical School, Southeast University, Nanjing, Jiangsu 210009, P.R. China
}

Received October 14, 2017; Accepted April 13, 2018

DOI: $10.3892 /$ or.2018.6391

\begin{abstract}
Cervical cancer is the third most common type of cancer in women, and microRNAs play an important role in this type of cancer. The elevated expression of miR-146a is involved in the pathogenesis of cancers generally, but its role in cervical cancer has not been fully elucidated. In the present study, we assessed the expression of miR-146a in $\mathrm{G}>\mathrm{C}$ polymorphisms and confirmed that the overexpression of miR146a promoted cervical cancer cell viability. The recombinant expression plasmids pre-miR-146a-G or pre-miR-146a-C including single nucleotide polymorphisms (SNP) were successfully constructed. Pre-miR-146a-G or pre-miR-146a-C was transfected into cervical cancer cells or immortalized non-tumorigenic cells and the expression of miR-146a was evaluated by real-time PCR. The cell viability, cell-cycle analysis and apoptosis were assessed using Cell Counting Kit-8 assay (CCK-8), flow cytometry and cleaved caspase-3 protein expression, respectively. The expression of interleukin 1 receptor associated kinase 1 (IRAK1), TNF receptor-associated factor 6 (TRAF6) and cyclin D1 was assessed following the transfection with a miR-146a mimic or a negative control. The cell viability and the number of S-phase cells increased after transfection with miR-146a mimic or an IRAK1 or TRAF6 interference fragment. After transfection, IRAK1 and TRAF6 protein expression was downregulated and the expression of cyclin D1 was upregulated, however apoptosis and cleaved caspase-3 were not affected. Polymorphisms in miR-146a precursor may be linked to the expression of miR146a and may be a potential target for cervical cancer therapy.
\end{abstract}

Correspondence to: Dr Suping Han, Department of Gynecology and Obstetrics, The First Affiliated Hospital of Nanjing Medical University, 300 Guangzhou Road, Nanjing, Jiangsu 210036, P.R. China

E-mail: hansupingnj@163.com

${ }^{*}$ Contributed equally

Key words: cervical cancer, miR-146a, IRAK1, TRAF6, cell viability

\section{Introduction}

Cervical cancer is the third most common cancer afflicting women, causing more than 500,000 new cancers and 274,000 deaths annually in the worldwide (1). With screening and treatment modalities such as chemotherapy, surgery and radiotherapy, cervical cancer incidence and mortality has decreased and survival has improved. However, an $~ 80 \%$ increase in new cases has been reported annually in developing countries and these cases are frequently advanced cancers $(2,3)$. Several studies have revealed that sexually active women are susceptible to the human papillomavirus (HPV) and that the majority of them are cured within 1-2 years. However, HPV can persist in the cervical epithelium and progress to cervical cancer (4). According to the available data women infected with HPV-16 and -18 subtypes tend to develop cervical cancer more often $(5,6)$.

miRNAs are small non-coding endogenous RNAs 19-25 nucleotides in length that bind to the 3'-untranslated region (3'-UTR) of their target mRNAs as gene regulators (7). miRNAs regulate gene expression by translational suppression or mRNA degradation and influence multiple cellular activities including viability, apoptosis and signal transduction $(5,8)$. Epidemiologic studies indicated that genetic variations in the host may also contribute to the pathogenesis of cervical cancer (9). For example, SNPs in miRNA precursors may alter the expression of mature miRNA and change target selection (10). miR-146a precursor SNP (rs2910164) involves a $\mathrm{G}>\mathrm{C}$ nucleotide substitution that changes a $\mathrm{G}: \mathrm{U}$ pair to a $\mathrm{C}: \mathrm{U}$ (11). Higher expression of miR-146a was observed in many solid types of cancer, such as melanoma, breast and lung cancer (12-14). A particular miR-146a was found to promote cellular viability (15-18). However, the functions of miR-146a in the development of cervical cancer remain unclear.

Multiple targets of miR-146a including interleukin (IL)-1 $\beta$, signal transducer, activator transcription 1 (Stat1), IRAK1 and TRAF6 were observed in several cancer cells and these targets are involved in cell viability, apoptosis and acute inflammatory responses (19-22). miR-146a was reported to limit IRAK1- and TRAF6-mediated signaling acts as a negative feedback regulator in inflammatory settings (23). IRAK1 and TRAF6 function as signal transducers in the nuclear factor- $\kappa \mathrm{B}$ 


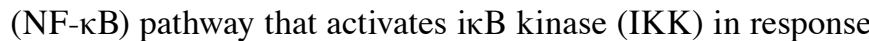
to pro-inflammatory cytokines (24). NF- $\kappa \mathrm{B}$ is known to be a significant signaling factor involved in the progression of cancers $(25,26)$. Considerable progress towards unraveling the molecular mechanisms underlying cervical cancer has been recently achieved, however the identification of potential novel therapeutic targets is necessary for improving the early detection and treatment of cervical cancer.

In the present study, to investigate latent functions of polymorphisms, we investigated the effect of SNP on the expression of miR-146a in cervical cancer cells, and assessed the association between miR-146a and both IRAK1 and TRAF6. We observed that the overexpression of miR-146a promoted the viability of cervical cancer cells via decreasing IRAK1 and TRAF6, providing new insights into understanding cervical cancer.

\section{Materials and methods}

Cell lines and sample collection. Immortalized nontumorigenic endocervical End1/E6E7 (CRL-2615) cells were purchased from the American Type Culture Collection (ATCC; Manassas, VA, USA) and cultured in keratinocyteserum free medium (Gibco-BRL 17005-042; Thermo Fisher Scientific, Inc., Waltham, MA, USA) with $0.1 \mathrm{ng} / \mathrm{ml}$ human recombinant EGF, $0.05 \mathrm{mg} / \mathrm{ml}$ bovine pituitary extract and additional calcium chloride $44.1 \mathrm{mg} / \mathrm{l}$ (final concentration $0.4 \mathrm{mM}$ ). HeLa and C-33A cervical cancer cells were obtained from the Shanghai Institute of Biochemistry and Cell Biology, Chinese Academy of Sciences (Shanghai, China). HeLa cells have been reported to contain human papilloma virus 18 (HPV-18) sequences, while C-33A cells and CRL-2615 were negative. Both HeLa and C-33A cells were cultured in DMEM (HyClone, Logan, UT, USA) supplemented with $10 \%$ fetal bovine serum (FBS; Sijiqing Biotechnology Co., Ltd., Hangzhou, China), $100 \mathrm{U} / \mathrm{ml}$ penicillin and $100 \mathrm{mg} / \mathrm{ml}$ streptomycin, in a humidified atmosphere containing $5 \% \mathrm{CO}_{2}$, at $37^{\circ} \mathrm{C}$.

Cervical cancer samples were obtained between January 2013 and January 2016 at the First Affiliated Hospital of Nanjing Medical University. Twenty cervical cancer tissues and fifteen specimens of normal cervical tissue were excised surgically from patients who had previously provided informed written consent. The study was approved by the Research Ethics Committee of Nanjing Medical University, and informed consent was obtained from all patients. Tumor samples and normal tissues were immediately frozen and stored at $-80^{\circ} \mathrm{C}$ until used. The tumor stage and grade was in consistence with the International Federation of Gynecologists and Obstetricians (FIGO).

Construction of the miRNA expression vector and cell transfection. To investigate the effect of SNP on the expression of miR-146a, pre-miR-146a consisting of a 370-bp DNA fragment was amplified from a genomic DNA sample with a miR-146a rs2910164 G allele or rs2910164 C allele, and cloned into pcDNA3.1(+) expression plasmid vector (Invitrogen Life Technologies, Carlsbad, CA, USA). Amplified DNA fragments were then sequenced to confirm that there were no mutations. For transfections, CRL-2615, HeLa and C-33A cells were transfected with expression plasmid vector containing either the $\mathrm{G}$ or $\mathrm{C}$ allele of miR-146a rs2910164 (pre-miR-146a-G or pre-miR-146a-C), using Lipofectamine 2000 (Invitrogen Life Technologies) according to the manufacturer's instructions. The pcDNA3.1(+) vector without an insert was used as a negative control. Transfection efficiency was verified by real-time PCR.

Quantitative real-time PCR. Total RNA was extracted from the cultured cells using TRIzol reagent (Takara, Otsu, Japan), according to the manufacturer's instructions. Bulge-loop miRNA quantitative real-time (qRT)-PCR primer sets specific for miR-146a were designed by Guangzhou RiboBio (Guangzhou, China) and expression levels were normalized against U6. The following primers were used: TRAF6 forward, 5'-TTTGCTCTTATGGATTGTCCCC-3' and reverse, 5'-CAT TGATGCAGCACAGTTGTC-3'; IRAK1 forward, 5'-TGAGG AACACGGTGTATGCTG-3' and reverse, 5'-GTTTGGGTG ACGAAACCTGGA-3'; GAPDH forward, 5'- GAAGGTCG GAGTCAACGGATTT-3' and reverse, 5'-CTGGAAGATG GTGATGGGATTTC-3'. cDNA was synthesized from $1 \mu \mathrm{g}$ total RNA using random primers and Superscript II Reverse Transcriptase (Takara) within $20 \mu \mathrm{l}$ reaction volumes. Quantitative real-time PCR was performed in an Applied Biosystems StepOne Real-time PCR system (Thermo Fischer Scientific), using SYBR-Green PCR kit (Takara) by normalizing to GAPDH. The $2^{-\Delta \Delta \mathrm{Ct}}$ method was used to analyze the relative miRNA or mRNA expression. All reactions were prepared in three independent experiments.

Western blotting. Cells were harvested in RIPA lysis buffer containing protease and phosphatase inhibitors, and the protein concentrations were determined by BCA protein assay (Beyotime Institute of Biotechnology, Shanghai, China). Protein samples were separated by $10 \%$ SDS-PAGE, and then transferred onto PVDF membranes (Millipore, Billerica, MA, USA), blocked with TBST containing 5\% skimmed milk for $1 \mathrm{~h}$ at $37^{\circ} \mathrm{C}$. Cells reacted with the following primary antibodies: rabbit anti-TRAF6 antibody (1:500; cat. no. BS3684; Bioworld Technology, Inc., St. Louis Park, MN, USA), rabbit anti-IRAK1 antibody (1:1,000; cat. no. BS1541; Bioworld Technology), mouse anti-cleaved caspase-3 antibody (1:1,000; cat. no. 9661; Cell Signaling Technology, Danvers, MA, USA), cyclin D1 (1:1,000; cat. no. 2922; Cell Signaling Technology) and mouse anti- $\beta$-actin antibody (1:5,000; cat. no. ab8226; Abcam, Cambridge, MA, USA). After being washed in TBST at room temperature, the membranes were incubated for $1 \mathrm{~h}$ at $37^{\circ} \mathrm{C}$ with a secondary HRP-conjugated antibody (1:5,000; Beijing ZhongShan Golden Bridge Biotechnology Co., Ltd., Beijing, China) and were visualized using an ECL detection kit (Amercontrol Biosciences, London, UK). Each experiment was performed in triplicate.

Identification of potential miR-146a targets and luciferase reporter assay. Potential targets of miR-146a were predicted and analyzed using TargetScan (http://www.targetscan.org), miRanda (http://www.microrna.org) and PicTar softwares (https://pictar.mdc-berlin.de). TargetScan Release 7.0 was the primary source for target identification and it offered 275 conserved targets, from which we selected 10 top targets 
A

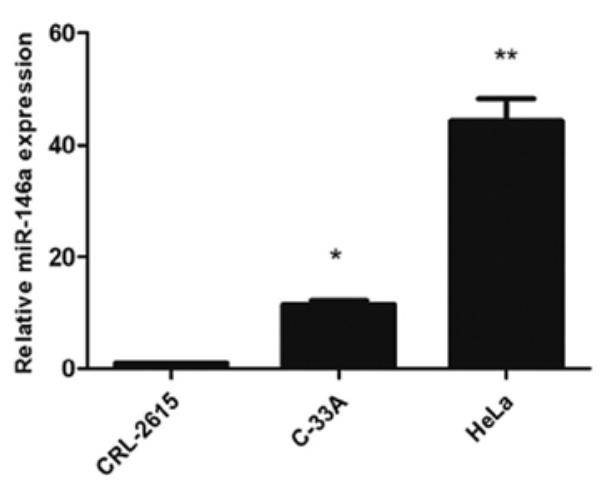

B

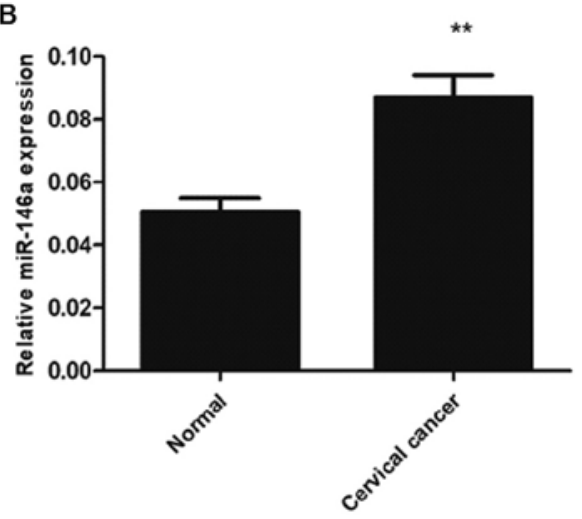

C

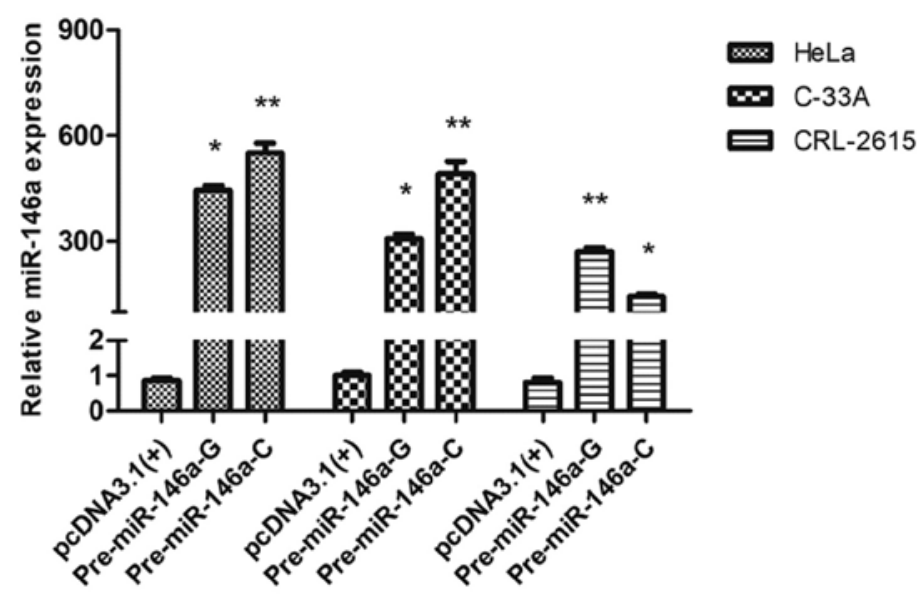

Figure 1. The expression of miR-146a in cervical cancer and the impact of SNP on the expression of miR-146a. (A) The expression of miR-146a in two cervical cancer cell lines and the immortalized non-tumorigenic endocervical End1/E6E7 (CRL-2615) cell line. (B) Comparison of the relative expression levels of miR-146a between cancer tissues and normal tissues. (C) The expression of miR-146a after being transfected with the recombinant expression plasmids in HeLa, C-33A and CRL-2615 cells. The expression of miR-146a mRNA was determined by qRT-PCR. Results are expressed as the mean \pm SD from triplicate independent experiments. ${ }^{*} \mathrm{P}<0.05,{ }^{* *} \mathrm{P}<0.01$.

with the highest aggregate P-value. miRanda and PicTar softwares were used to predict potential targets based on mirSVR scores $<1.50$ and PicTar scores $>5.0$. A wild-type 3'-UTR of the IRAK1 or TRAF6 gene was cloned into the pMIR-Report luciferase vector (Promega, Madison, WI, USA). Constructs carrying the mutated fragment of the 3'-UTR of IRAK1 and TRAF6 mRNA without the putative miR-146a binding sequences were used as the mutated controls. Subsequently, 293 cells were transfected with the reporter constructs together with a miR-146a-5p mimic or negative control (NC), using Lipofectamine 2000 (Invitrogen Life Technologies). Cells were harvested after $48 \mathrm{~h}$ and the activity was assessed using a Modulus $^{\mathrm{TM}}$ luminometer (Turner Biosystems; Thermo Fisher Scientific). Renilla luciferase activity was used as a control for transfection efficiency. All assays were conducted in triplicate and the experiments were prepared in three independent experiments. IRAK1 and TRAF6 genes were also verified in other malignancies as previously reported (20).

Cell viability assay and cell-cycle analysis. HeLa and C-33A cells were cultured at a density of 10,000 cells/well in 96-well plates. Cell culture continued for 24,48 and $72 \mathrm{~h}$ after transfection, and cell viability were performed using a Cell Counting Kit-8 (CCK-8; Dojindo Laboratories, Kumamoto, Japan) according to the manufacturer's instructions. The absorbance value of each well was assessed at $450 \mathrm{~nm}$ in a microplate reader. The data were obtained from five independent cultures and experiments were repeated in triplicate.

Forty-eight hours after transfection, cells were harvested and washed twice with cold PBS, and the supernatant was removed after centrifugation. Subsequently, the cells were collected and fixed in $75 \%$ ice-cold ethanol and incubated at $-20{ }^{\circ} \mathrm{C}$ overnight. After being washed, they were stained with $50 \mathrm{mg} / \mathrm{ml}$ of propidium iodide (PI) for DNA content analysis by flow cytometry on a FACSCalibur system (BD Biosciences, Franklin Lakes, NJ, USA). Results were expressed as a percentage of cells in each cell-cycle phase.

Apoptosis analysis. Cells were lifted off the plates, washed twice with PBS and determined with an Annexin V-FITC/ propidium iodide (PI) kit (BD Biosciences) at room temperature for $15 \mathrm{~min}$ in the dark, and then analyzed by BD Biosciences FACS Calibur Flow Cytometry (BD Biosciences) according to the manufacturer's protocol. All experiments were performed independently, in triplicate.

Statistical analysis. SPSS 18.0 software (SPSS, Inc., Chicago, IL, USA) was used for statistical analysis. The results are represented as the means \pm SD from three separate experiments or more. Statistical analysis was performed by ANOVA for 
A

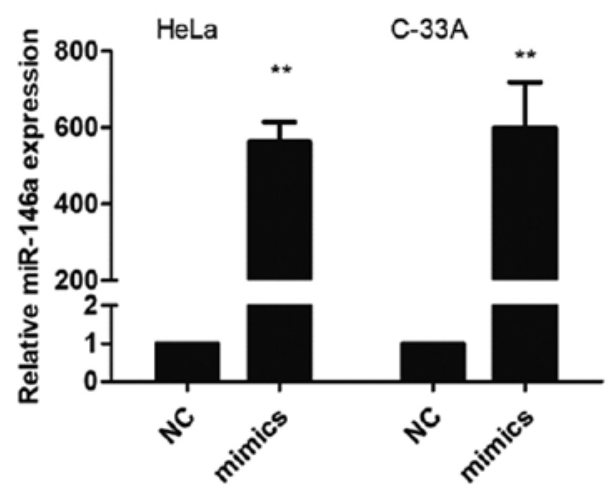

B

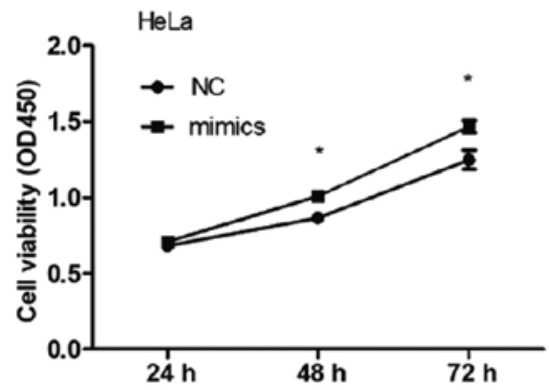

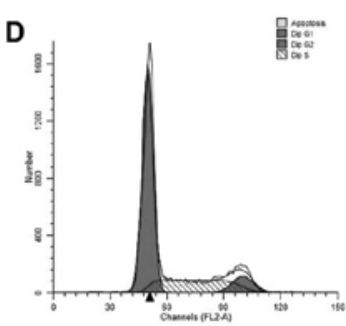

NC

E

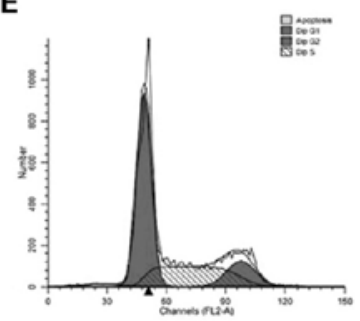

NC

$\mathbf{F}$

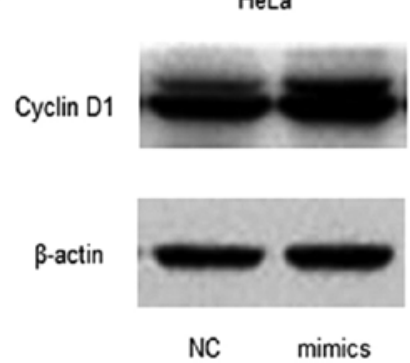

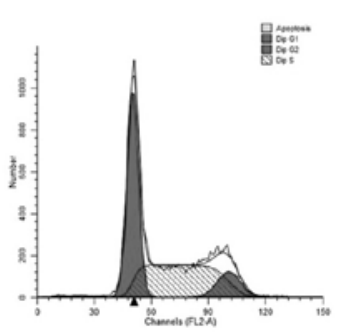

mimics

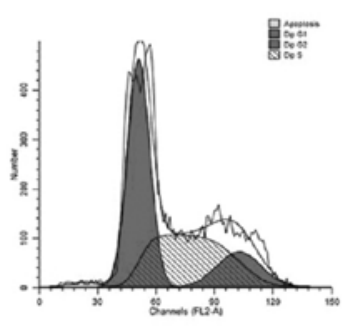

mimics

C.33A

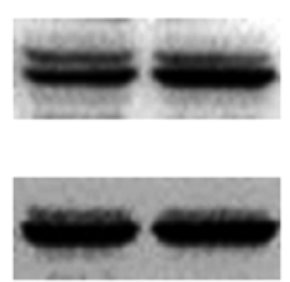

NC
C
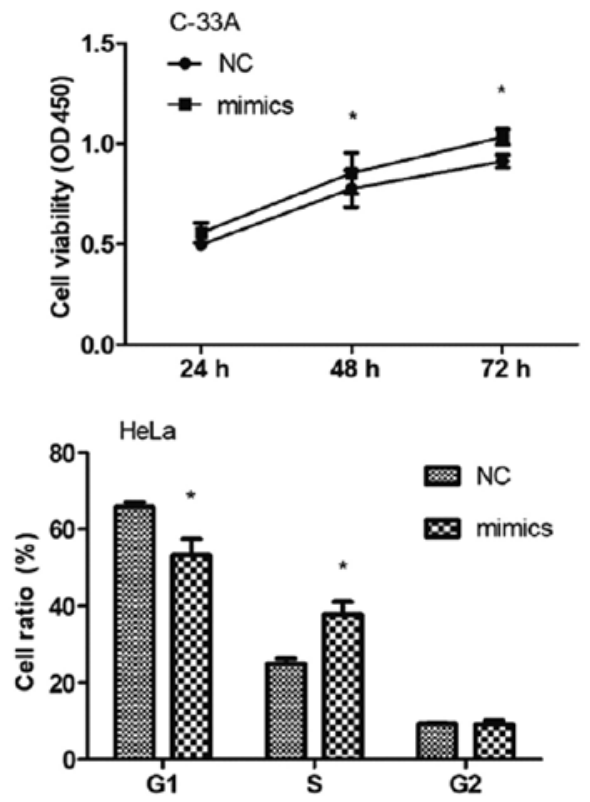

C-33A
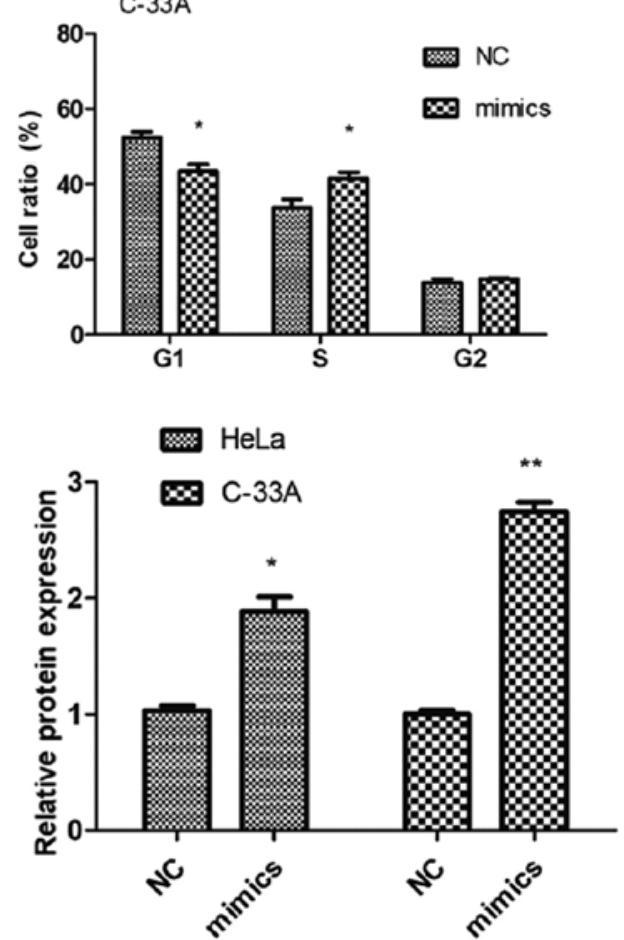

Figure 2. Effect of miR-146a on cell viability and cell cycle in HeLa and C-33A cells. Cervical cancer cells were infected with 100 nM each of miR-146a mimics or miR-146a NC for 48 h. (A) The miR-146a level was assessed by qRT-PCR. (B and C) The effect of miR-146a on cell viability was assessed by CCK-8 assay following transfection with miR-146a NC or mimics. (D and E) The effect of miR-146a on the cell cycle in HeLa and C-33A cells. Transfected cells were stained with PI and analyzed by flow cytometry. (F) The protein level of cyclin D1 was assayed by western blotting. $\beta$-actin was used as a loading control. The results are demonstrated as the mean \pm SD from triplicate independent experiments. ${ }^{*} \mathrm{P}<0.05,{ }^{* *} \mathrm{P}<0.01$. mimics, miR-146a mimics; $\mathrm{NC}, \mathrm{miR}-146 \mathrm{a}$ negative control. 
A

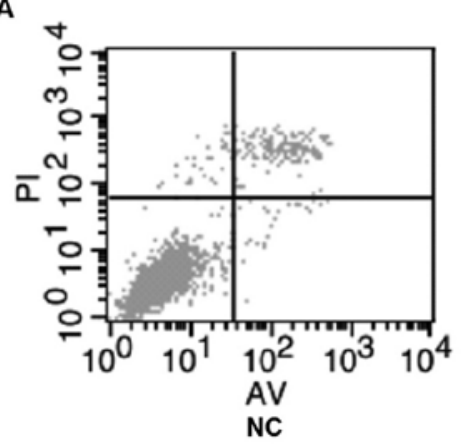

B

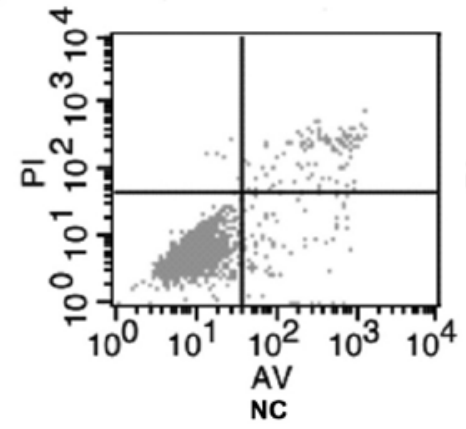

C

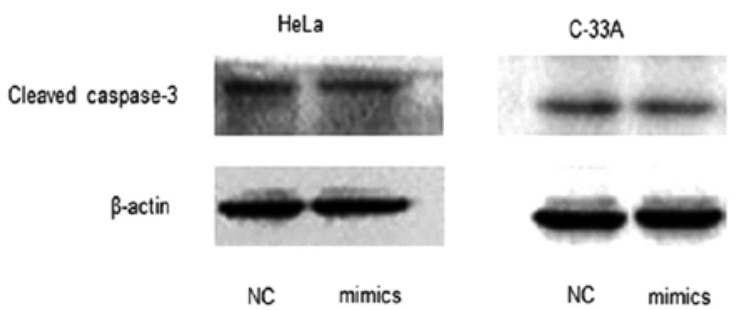

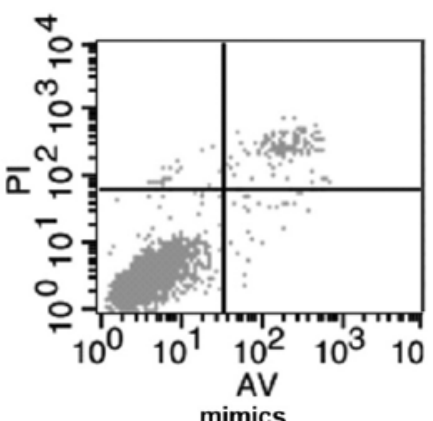
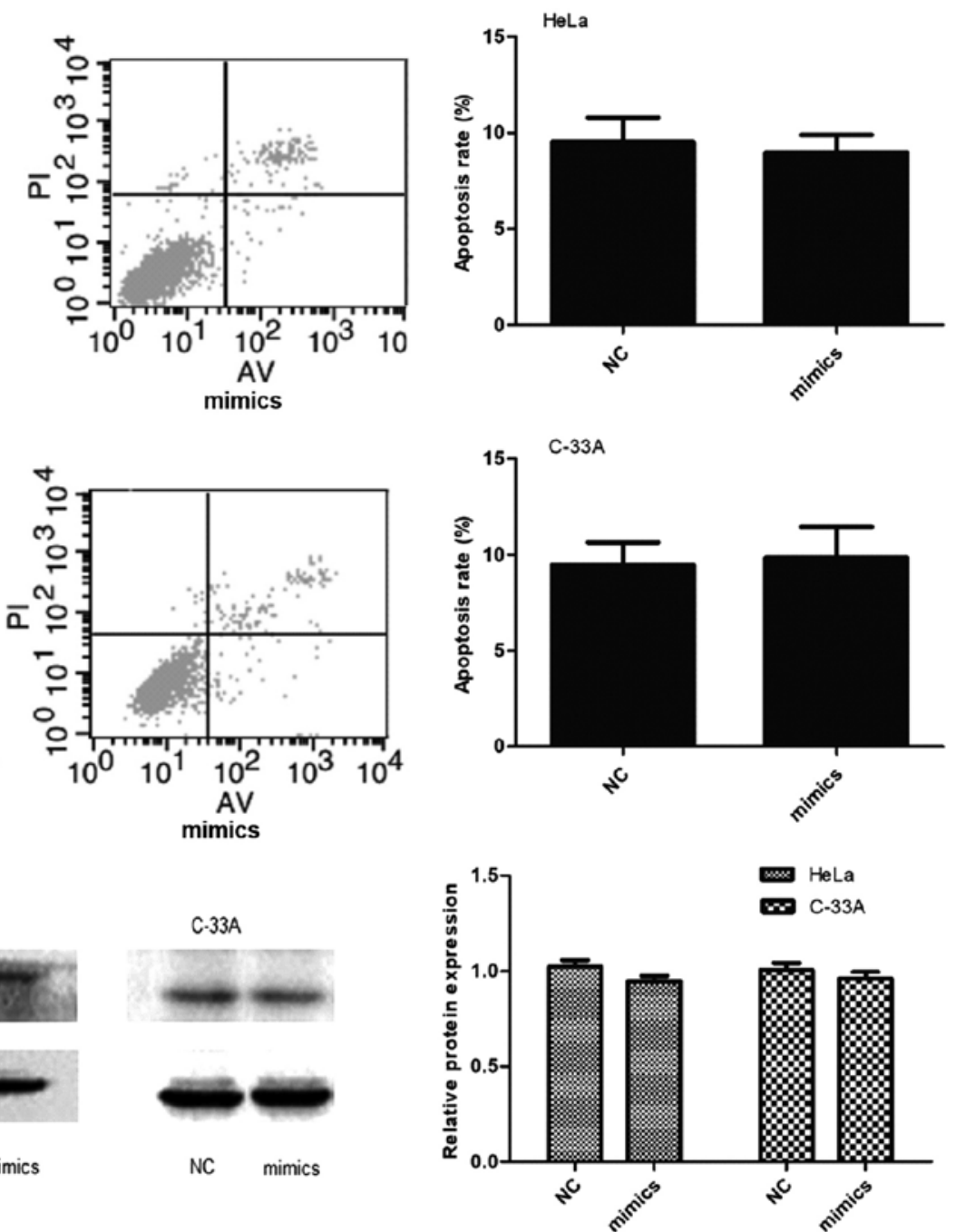

Figure 3. Effect of miR-146a on apoptosis. Ectopic miR-146a demonstrated no significant decrease on apoptosis. (A and B) The levels of apoptosis were determined by Annexin V and PI staining. (C) The protein level of cleaved caspase-3 was assayed by western blotting. $\beta$-actin was used as a loading control. mimics, miR-146a mimics; NC, miR-146a negative control.

experiments involving more than two groups. The two-tailed Student's t-test was performed for comparisons with two groups and $\mathrm{P}<0.05$ was considered to indicate a statistically significant difference $\left({ }^{*} \mathrm{P}<0.05 ;{ }^{* *} \mathrm{P}<0.01\right)$.

\section{Results}

The expression of miR-146a in cervical cancer and impact of SNP on the expression of miR-146a. Two types of human cervical cancer cells were first analyzed to quantify the expression levels of miR-146a. Our results revealed that the expression of miR-146a was increased in these two cell lines compared with the immortalized non-tumorigenic CRL-2615 cell line (Fig. 1A). Subsequently, we assessed the expression levels of miR-146a in 20 cervical cancer tissues and 15 normal cervical tissue samples. The results demonstrated that the expression of miR-146a was significantly upregulated in cancer tissues than that in normal tissues $(\mathrm{P}<0.01$, Fig. 1B). Collectively, these results indicated that the high expression of miR-146a may be involved as an oncogene in cervical cancer.

Transfection of recombinant expression plasmids into HeLa and C-33A cervical cancer cell lines and the immor- talized non-tumorigenic CRL-2615 cell line revealed that the expression of miR-146a was higher with the $\mathrm{C}$ allele compared to the $\mathrm{G}$ allele in HeLa and $\mathrm{C}-33 \mathrm{~A}$ cells, while the expression of miR-146a was lower with the $\mathrm{C}$ allele compared to the G allele in CRL-2615 cells (Fig. 1C). Thus the expression of miR-146a was upregulated in cervical cancer, and the $\mathrm{G}>\mathrm{C}$ substitution in pre-miR-146a increased mature miR-146a expression in cervical cancer cells, but exerted the opposite effect in CRL-2615 cells.

Ectopic miR-146a effects on cell viability and cervical cancer cell cycle. To explore the effect of miR-146a in cervical cancer carcinogenesis, HeLa and C-33A cells were transiently transfected with miR-146a mimic or negative control, and assessed for the expression of miR-146a (Fig. 2A). miR-146a significantly promoted cell growth in HeLa and C-33A cells (Fig. 2B and $\mathrm{C}$ ), indicating that miR-146a exerted a growth-promoting function in cervical cancer cells.

Given that miR-146a promotes the viability of cervical cancer cells, we examined whether miR-146a influenced the cell cycle progression of cervical cancer cells. The number of cells in the G1 phase was significantly decreased after transfection 
A

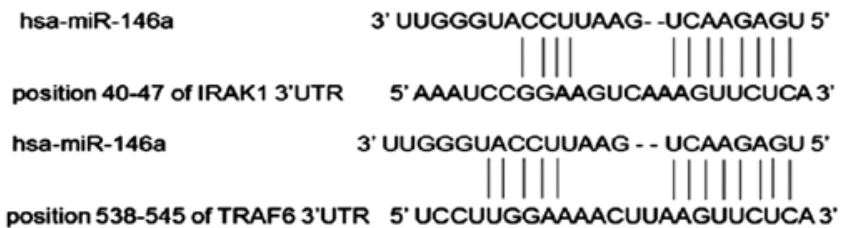

B

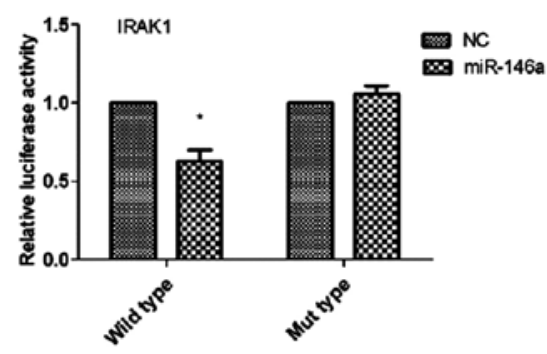

D

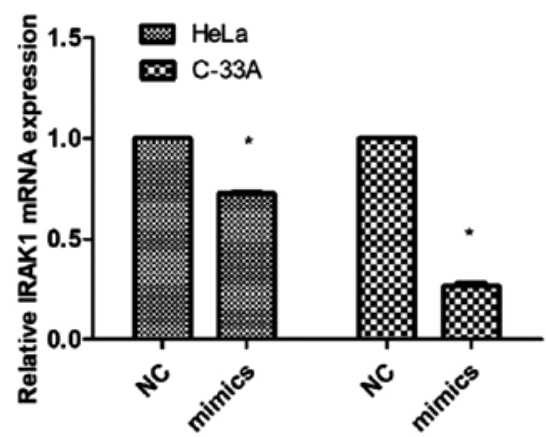

$\mathbf{F}$

IRAK1

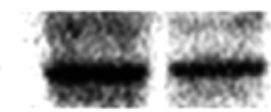

$\beta$-actin

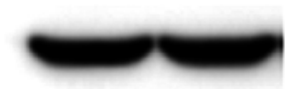

NC

mimics

G

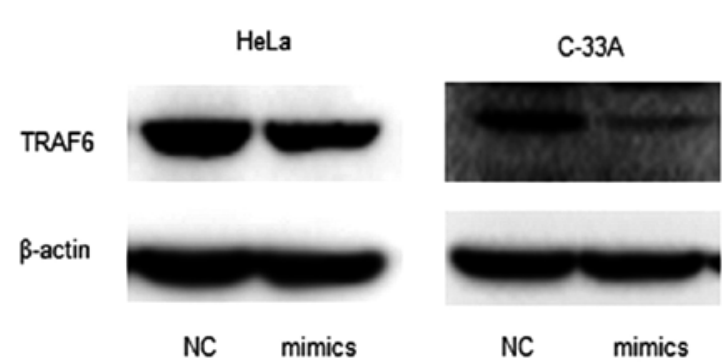

C

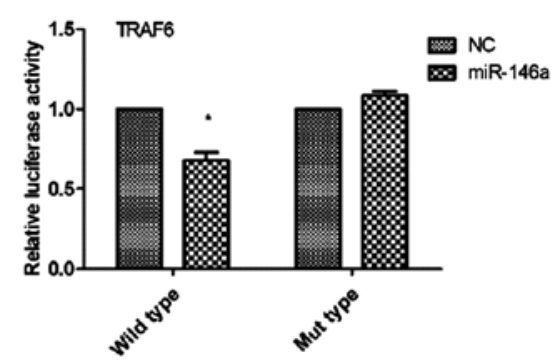

E
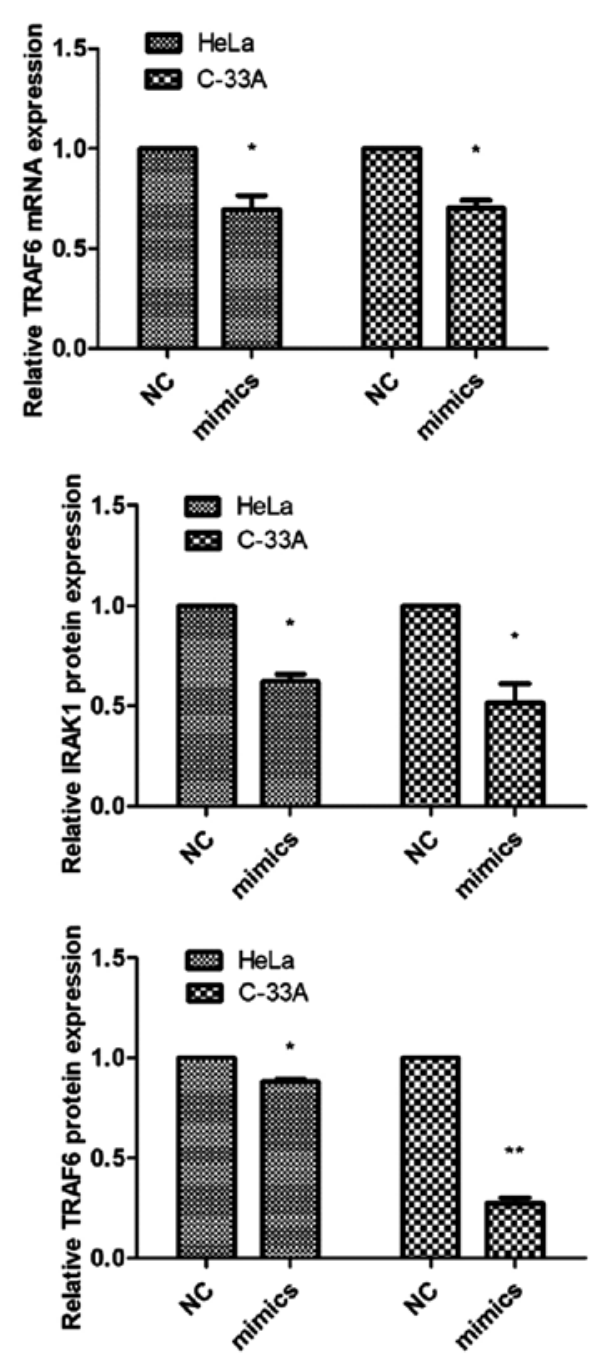

Figure 4. miR-146a regulates the expression of IRAK1 and TRAF6. (A) The putative binding sites for human miR-146a in the 3'UTR of IRAK1 and TRAF6 mRNA. (B and C) The overexpression of miR-146a led to a significant reduction in the luciferase activity of the wild-type IRAK1 and TRAF6 3 ' UTR reporter gene. (D and E) miR-146a reduced the expression of IRAK1 and TRAF6 mRNA in cervical cancer cells, as well as (F and G) IRAK1 and TRAF6 protein expression. The IRAK1 and TRAF6 mRNA level was assessed by qRT-PCR, protein expression was assessed by western blotting. Results are shown as the mean $\pm \mathrm{SD}$ of triplicate independent experiments. ${ }^{*} \mathrm{P}<0.05,{ }^{* *} \mathrm{P}<0.01$. mimics, miR-146a mimics; NC, miR-146a negative control.

with miR-146a mimic in HeLa ( $\mathrm{P}=0.048)$ and $\mathrm{C}-33 \mathrm{~A}(\mathrm{P}=0.022)$ cells, while cells in the $\mathrm{S}$ phase were increased in HeLa cells $(\mathrm{P}=0.018)$ and in $\mathrm{C}-33 \mathrm{~A}$ cells $(\mathrm{P}=0.046)$ compared to the controls (Fig. 2D and E). Therefore, we hypothesized that miR-146a enhanced growth by promoting cell cycle progression at the G1-to-S-phase transition. The expression of the 


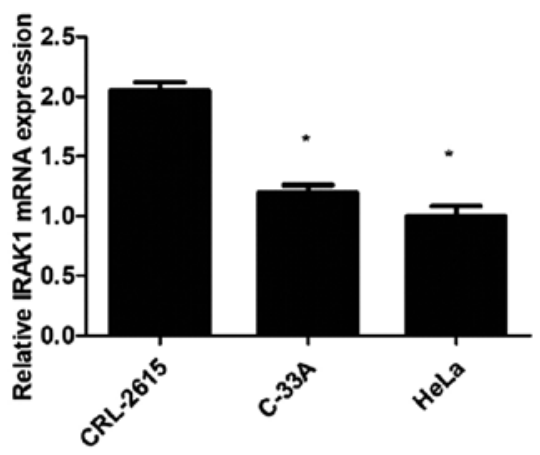

C

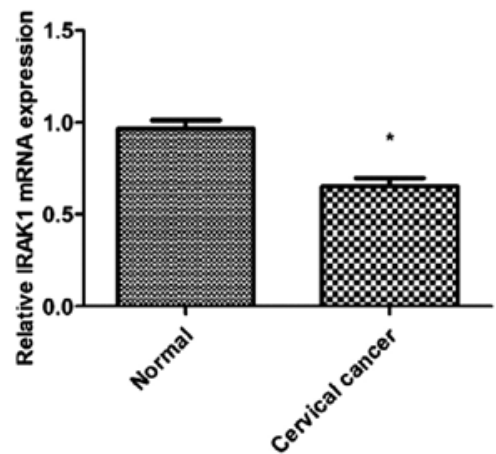

E

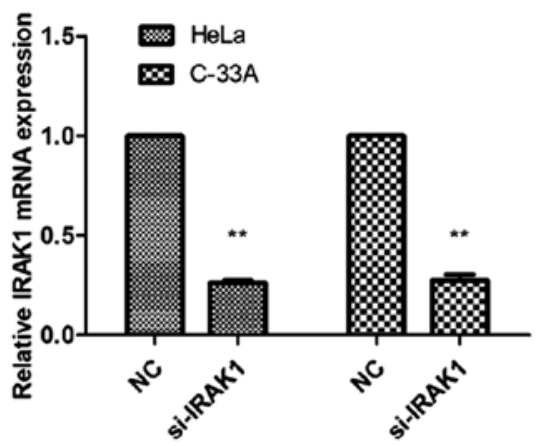

G

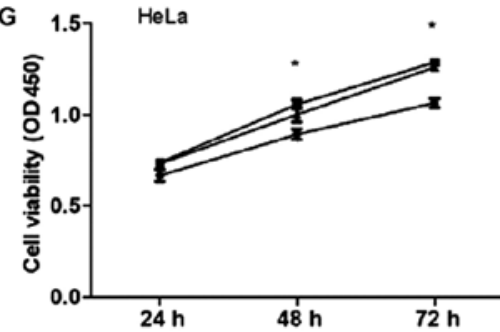

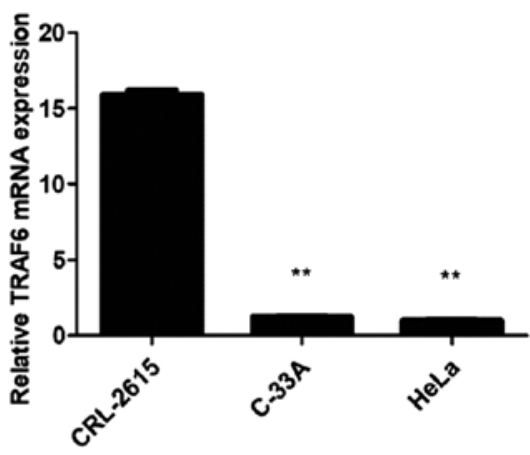

D

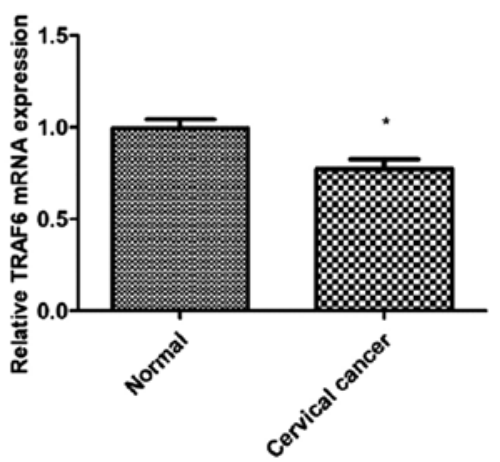

F

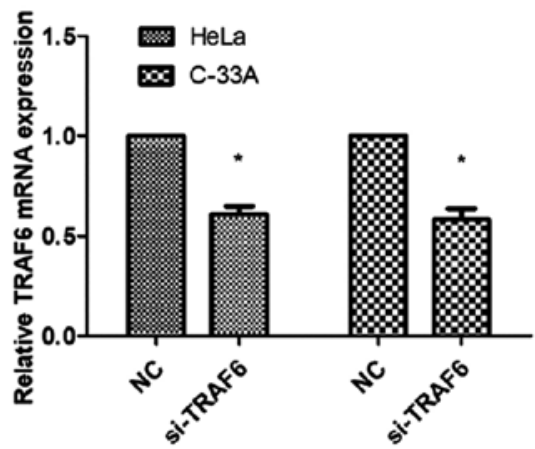

H

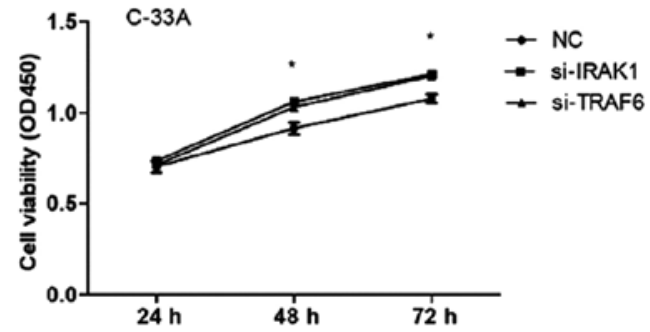

Figure 5. miR-146a promotes cell viability by targeting IRAK1 and TRAF6. (A and B) The expression of IRAK1 and TRAF6 mRNA in two cervical cancer cells and CRL-2615. (C and D) The mRNA expression levels of IRAK1 and TRAF6 in cervical cancer tissues. (E and F) IRAK1 and TRAF6 siRNAs were infected in cervical cancer cells to downregulate the mRNA expression of IRAK1 and TRAF6. (G and H) The effect of si-IRAK1 and si-TRAF6 on cell viability was assessed by CCK- 8 assay after transfecting with si-IRAK1 and si-TRAF6. The IRAK1 and TRAF6 mRNA level was assessed by qRT-PCR. The results are shown as the mean $\pm \mathrm{SD}$ from triplicate independent experiments. ${ }^{*} \mathrm{P}<0.05,{ }^{* * *} \mathrm{P}<0.01$. si-IRAK1, IRAK1 siRNA; si-TRAF6, TRAF6 siRNA; NC, si-RNA negative control.

oncogene cyclin D1 in HeLa and C-33A cells was also upregulated following the miRNA-146a mimic transfection (Fig. 2F), indicating that miRNA-146a may be an oncogenic regulator in cervical cancer cells.

Effects of ectopic miR-146a on apoptosis of cervical cancer cells. The number of early apoptotic cells was assessed by flow cytometry and was not significantly decreased in
miR-146a mimic transfected cervical cancer cells (Fig. 3A and $\mathrm{B}, \mathrm{P}>0.05$ ). Western immunoblotting analysis confirmed that cleaved caspase-3 protein was not decreased in either cell line after miR-146a overexpression (Fig. 3C, P>0.05). Thus, miR-146a in cervical cancer cells does not modify apoptosis.

IRAK1 and TRAF6 are direct targets of miR-146a in cervical cancer cells. The use of target prediction tools such as 
TargetScan, miRanda and PicTar predicted that miR-146a was a putative regulator of IRAK1 and TRAF6 (Fig. 4A). To confirm that IRAK1 and TRAF6 were targets of miR-146a, we generated a pMIR-Report luciferase vector containing wild-type 3'-UTR of the IRAK1 and TRAF6 genes. We co-transfected these constructs into 293 cells together with a miR-146a mimic or negative control, and then conducted luciferase activity assays. As displayed in Fig. 4B and C, compared with the control, the overexpression of miR-146a led to a significant reduction in the luciferase activity of the wildtype IRAK1 and TRAF6 3'UTR reporter gene in 293 cells (IRAK1 wild-type, TRAF6 wild-type, $\mathrm{P}<0.05$ ). To explore the mechanism of viability promotion induced by miR-146a, we investigated whether miR-146a regulated the expression of IRAK1 and TRAF6 in cervical cancer cells. Following miR146a mimic transfection, the expression of IRAK1 and TRAF6 mRNA ( $\mathrm{P}<0.05$; Fig. 4D and $\mathrm{E})$ and the protein expression $(\mathrm{P}<0.05$; Fig. 4F and $\mathrm{G})$ were decreased with ectopic expression of miR-146a.

miR-146a promotes cell viability by targeting IRAKI and TRAF6. In HeLa and C-33A cells, the expression of IRAK1 and TRAF6 mRNA was assessed and found decreased compared with CRL-2615 cells (Fig. 5A and B). There was no difference between the HeLa and C-33A cells. RT-PCR was used to investigate the mRNA expression levels of IRAK1 and TRAF6 in cervical cancer tissues $(\mathrm{n}=20)$ and normal cervical tissues $(n=15)$. Both IRAK1 and TRAF6 mRNA expression levels were significantly downregulated in cervical cancer tissues (Fig. 5C and D). To investigate whether IRAK1 and TRAF6 were involved in miR-146a-mediated viability of cervical cancer cells, we infected cervical cancer cells with IRAK1 and TRAF6 siRNAs to downregulate IRAK1 and TRAF6 (Fig. 5E and F). The CCK-8 assay demonstrated that si-IRAK1 and si-TRAF6 significantly promoted cell viability in HeLa and C-33A cells ( $\mathrm{P}<0.05$; Fig. 5G and $\mathrm{H})$. These findings supported our contention that miR-146a in cervical cancer cells promoted tumor cell viability by inhibiting IRAK1 and TRAF6.

\section{Discussion}

Understanding tumor cell viability and its underlying mechanisms can assist us in developing effective therapeutic strategies that improve survival for patients with cancer. In this context, miRNAs have been reported to be associated with cancer cell viability, apoptosis, differentiation, adhesion and migration $(5,8,27)$. Wang et al (28) used miRNA array analyses to compare age-matched normal and cervical cancer tissues and demonstrated that miR-146a was upregulated in cervical cancer tissues, and that overexpression of miR-146a promoted cell viability, while Sathyanarayanan et al (29) reported that miR-146a inhibited viability, migration and invasion of human cervical cancer cells. This could be due to the different cervical cancer cells and diverse trials in their study. In the present study, we reported that the expression of miR-146a increased in cervical cancer cells compared with immortalized non-tumorigenic endocervical cells, and that the expression of miR-146a was greater in HPV-18 sequencepositive HeLa cells than in HPV-18 sequence-negative C-33A cells. Furthermore, miR-146a gain-of-function tests confirmed that miR-146a acted as a tumor promoter in our study, and were in accordance with the study of Wang et al (28).

Sequence variations in miRNA genes, including primiRNAs and pre-miRNAs, could potentially influence the processing of miRNAs (30). The miRNA-146a precursor SNP (rs2910164) affects the expression of mature miR-146a and contributes to a genetic predisposition toward papillary thyroid carcinoma (11). Preliminary evidence indicated that these effects were mediated through target genes that included papillary thyroid carcinoma 1 gene (PTC1), IRAK1 and TRAF6, and that the $\mathrm{C}$ allele of mature miR-146a was less effective in inhibiting these target genes $(11,23)$. We have previously reported that in cervical cancer tissue, the miR-146a $\mathrm{G}>\mathrm{C}$ polymorphism led to increased production of miR-146a, and that the GG genotype was associated with a higher risk of cervical cancer (31). In the present study, we discovered that after transfection with recombinant plasmids, the expression of miR-146a was higher in the $\mathrm{C}$ allele compared to the $\mathrm{G}$ allele in cervical cancer cells, while miR-146a expression was reduced 2 -fold with respect to the $\mathrm{C}$ allele, compared to the $\mathrm{G}$ allele in CRL-2615 cells. The effect of SNP was not consistent in cervical cancer cells and immortalized nontumorigenic endocervical cells.

$\mathrm{NF}-\mathrm{\kappa B}$ is a significant signaling factor involved in the development and progression of human cancers and it is the key protein that has been documented as the critical target for therapy in human cancers $(25,32,33)$. NF- $\kappa \mathrm{B}$ has a key role in the innate and adaptive immune response of the host and acts as a tumor suppressor in the initial stages of HPV infection in cervical cancer cells, but appears to be downregulated during cancer initiation (33). During the classical NF- $\kappa B$ activation pathway, IRAK1 and TRAF6 were key regulators that induced the upregulation of the transcription factor NF- $\mathrm{KB}$ activity. Downregulation of IRAK1 and TRAF6 inhibited TNF- $\alpha$-induced NF- $\kappa B$ activation (34). Bhaumik et al (24) reported that miR-146a acted as a negative regulator of NF- $\kappa \mathrm{B}$ activity by reducing the metastatic potential of breast cancer cells. miR-146a prevented the activation of NF- $\mathrm{KB}$ by targeting IRAK1 and TRAF6 in cardiomyocytes and inflammatory monocytic cells (35). In the present study we reported that the overexpression of miR-146a contributed to cervical cancer carcinogenic processes via targeting IRAK1 and TRAF6. In addition, overexpression of miR-146a decreased the expression of cyclin D1 which is an index of cell-cycle progression. The downregulation of IRAK1 and TRAF6 inhibited the NF- $\mathrm{KB}$ activity which inhibited cell growth, probably allowing HPV persistence and eventually, the development of cervical cancer.

Liu et al (13) observed that miR-146a can prevent tumor cell viability and enhance apoptosis as a tumor suppressor by negatively regulating constitutive NF- $\mathrm{\kappa B}$ activity in breast cancer cells. However, aberrant expression of miR-146a did not affect apoptosis in our study. Thus, the function of miR146a may be dependent on the cell type.

In conclusion, polymorphisms in miR-146a precursor may be linked to the expression of miR-146a and may be a potential target for cervical cancer therapy. As the etiology of cervical cancer remains elusive, additional studies are required to confirm our present findings. 


\section{Acknowledgements}

Not applicable.

\section{Funding}

The present study was supported in part by a grant from the Natural Science Foundation of Jiangsu Province (no. BK2012878).

\section{Availability of data and materials}

The datasets used during the present study are available from the corresponding author upon reasonable request.

\section{Authors' contributions}

SH and BD conceived and designed the study. QH, JS and JL performed the experiments. QH wrote the manuscript. YC and $\mathrm{SH}$ reviewed and edited the manuscript. QH and JS contributed equally. All authors read and approved the manuscript and agree to be accountable for all aspects of the research in ensuring that the accuracy or integrity of any part of the work are appropriately investigated and resolved.

\section{Ethics approval and consent to participate}

The study was approved by the Research Ethics Committee of Nanjing Medical University. Informed consent was obtained from all patients.

\section{Consent for publication}

Not applicable.

\section{Competing interests}

The authors declare that they have no competing interests.

\section{References}

1. Siegel R, Naishadham D and Jemal A: Cancer statistics, 2012. CA Cancer J Clin 62: 10-29, 2012.

2. de Freitas AC, Gomes Leitão MC and Coimbra EC: Prospects of molecularly-targeted therapies for cervical cancer treatment. Curr Drug Targets 16: 77-91, 2015.

3. Ferlay J, Soerjomataram I, Dikshit R, Eser S, Mathers C, Rebelo M, Parkin DM, Forman D and Bray F: Cancer incidence and mortality worldwide: Sources, methods and major patterns in GLOBOCAN 2012. Int J Cancer 136: E359-E386, 2015.

4. Schiffman M, Castle PE, Jeronimo J, Rodriguez AC and Wacholder S: Human papillomavirus and cervical cancer. Lancet 370: 890-907, 2007.

5. Scheurer ME, Tortolero-Luna G and Adler-Storthz K: Human papillomavirus infection: Biology, epidemiology, and prevention. Int J Gynecol Cancer 15: 727-746, 2005.

6. Castellsagué X, Naud P, Chow SN, Wheeler CM, Germar MJ, Lehtinen M, Paavonen J, Jaisamrarn U, Garland SM, Salmerón J, et al: Risk of newly detected infections and cervical abnormalities in women seropositive for naturally acquired human papillomavirus type 16/18 antibodies: Analysis of the control arm of PATRICIA. J Infect Dis 210: 517-534, 2014.

7. Bartel DP: MicroRNAs: Genomics, biogenesis, mechanism, and function. Cell 116: 281-297, 2004.

8. Murchison EP, Stein P, Xuan Z, Pan H, Zhang MQ, Schultz RM and Hannon GJ: Critical roles for Dicer in the female germline. Genes Dev 21: 682-693, 2007.
9. Magnusson PK, Lichtenstein P and Gyllensten UB: Heritability of cervical tumours. Int J Cancer 88: 698-701, 2000.

10. Wu M, Jolicoeur N, Li Z, Zhang L, Fortin Y, L'Abbe D, Yu Z and Shen SH: Genetic variations of microRNAs in human cancer and their effects on the expression of miRNAs. Carcinogenesis 29: 1710-1716, 2008.

11. Jazdzewski K, Murray EL, Franssila K, Jarzab B, Schoenberg DR and de la Chapelle A: Common SNP in pre-miR-146a decreases mature miR expression and predisposes to papillary thyroid carcinoma. Proc Natl Acad Sci USA 105: 7269-7274, 2008.

12. Zavala V, Pérez-Moreno E, Tapia T, Camus M and Carvallo P: miR-146a and miR-638 in BRCA1-deficient triple negative breast cancer tumors, as potential biomarkers for improved overall survival. Cancer Biomark 16: 99-107, 2016.

13. Liu R, Liu C, Chen D, Yang WH, Liu X, Liu CG, Dugas CM, Tang F, Zheng P, Liu Y, et al: FOXP3 Controls an miR-146/ NF-кB Negative Feedback Loop That Inhibits Apoptosis in Breast Cancer Cells. Cancer Res 75: 1703-1713, 2015.

14. Zhang S, Liu F, Mao X, Huang J, Yang J, Yin X, Wu L, Zheng L and Wang Q: Elevation of miR-27b by HPV16 E7 inhibits PPAR $\gamma$ expression and promotes proliferation and invasion in cervical carcinoma cells. Int J Oncol 47: 1759-1766, 2015.

15. Liu F, Zhang S, Zhao Z, Mao X, Huang J, Wu Z, Zheng L and Wang Q: MicroRNA-27b up-regulated by human papillomavirus 16 E7 promotes proliferation and suppresses apoptosis by targeting polo-like kinase 2 in cervical cancer. Oncotarget 7: 19666-19679, 2016.

16. Peralta-Zaragoza O, Deas J, Meneses-Acosta A, De la O-GómezF, Fernández-Tilapa G, Gómez-Cerón C, Benítez-Boijseauneau O, Burguete-García A, Torres-Poveda K, Bermúdez-Morales VH, et al: Relevance of miR-21 in regulation of tumor suppressor gene PTEN in human cervical cancer cells. BMC Cancer 16: 215,2016

17. Leung CO, Deng W, Ye TM, Ngan HY, Tsao SW, Cheung AN, Pang RT and Yeung WS: miR-135a leads to cervical cancer cell transformation through regulation of $\beta$-catenin via a SIAH1dependent ubiquitin proteosomal pathway. Carcinogenesis 35: 1931-1940, 2014.

18. Zhou X, Yue Y, Wang R, Gong B and Duan Z: MicroRNA-145 inhibits tumorigenesis and invasion of cervical cancer stem cells. Int J Oncol 50: 853-862, 2017.

19. Hwang WL, Jiang JK, Yang SH, Huang TS, Lan HY, Teng HW, Yang CY, Tsai YP, Lin CH, Wang HW, et al: MicroRNA-146a directs the symmetric division of Snail-dominant colorectal cancer stem cells. Nat Cell Biol 16: 268-280, 2014.

20. Park H, Huang X, Lu C, Cairo MS and Zhou X: MicroRNA-146a and microRNA-146b regulate human dendritic cell apoptosis and cytokine production by targeting TRAF6 and IRAK1 proteins. J Biol Chem 290: 2831-2841, 2015 .

21. Perry MM, Moschos SA, Williams AE, Shepherd NJ, Larner-Svensson HM and Lindsay MA: Rapid changes in microRNA-146a expression negatively regulate the IL-1betainduced inflammatory response in human lung alveolar epithelial cells. J Immunol 180: 5689-5698, 2008.

22. Contreras JR, Palanichamy JK, Tran TM, Fernando TR, Rodriguez-Malave NI, Goswami N, Arboleda VA, Casero D and Rao DS: MicroRNA-146a modulates B-cell oncogenesis by regulating Egr1. Oncotarget 6: 11023-11037, 2015.

23. Hou J, Wang P, Lin L, Liu X, Ma F, An H, Wang Z and Cao X: MicroRNA-146a feedback inhibits RIG-I-dependent Type I IFN production in macrophages by targeting TRAF6, IRAK1, and IRAK2. J Immunol 183: 2150-2158, 2009.

24. Bhaumik D, Scott GK, Schokrpur S, Patil CK, Campisi J and Benz CC: Expression of microRNA-146 suppresses NF-kappaB activity with reduction of metastatic potential in breast cancer cells. Oncogene 27: 5643-5647, 2008.

25. Ito-Kureha $\mathrm{T}$, Koshikawa N, Yamamoto M, Semba K, Yamaguchi N, Yamamoto T, Seiki M and Inoue J: Tropomodulin 1 expression driven by NF- $\mathrm{KB}$ enhances breast cancer growth. Cancer Res 75: 62-72, 2015.

26. Kastrati I, Canestrari E and Frasor J: PHLDA1 expression is controlled by an estrogen receptor-NFKB-miR-181 regulatory loop and is essential for formation of $\mathrm{ER}^{+}$mammospheres. Oncogene 34: 2309-2316, 2015.

27. McManus MT: MicroRNAs and cancer. Semin Cancer Biol 13: 253-258, 2003

28. Wang X, Tang S, Le SY, Lu R, Rader JS, Meyers C and Zheng ZM: Aberrant expression of oncogenic and tumor-suppressive microRNAs in cervical cancer is required for cancer cell growth. PLoS One 3: e2557, 2008. 
29. Sathyanarayanan A, Chandrasekaran KS and Karunagaran D: microRNA-146a inhibits proliferation, migration and invasion of human cervical and colorectal cancer cells. Biochem Biophys Res Commun 480: 528-533, 2016.

30. Duan R, Pak C and Jin P: Single nucleotide polymorphism associated with mature miR-125a alters the processing of pri-miRNA Hum Mol Genet 16: 1124-1131, 2007.

31. Yue C, Wang M, Ding B, Wang W, Fu S, Zhou D, Zhang Z and Han S: Polymorphism of the pre-miR-146a is associated with risk of cervical cancer in a Chinese population. Gynecol Oncol 122: 33-37, 2011.

32. Sarkar FH, Li Y, Wang Z and Kong D: Cellular signaling perturbation by natural products. Cell Signal 21: 1541-1547, 2009.
33. Lin Y, Bai L, Chen W and Xu S: The NF-kappaB activation pathways, emerging molecular targets for cancer prevention and therapy. Expert Opin Ther Targets 14: 45-55, 2010.

34. Kim JE, Kim SY, Lim SY, Kieff E and Song YJ: Role of $\mathrm{Ca}^{2+}$ calmodulin-dependent kinase II-IRAK1 interaction in LMP1induced NF- $\kappa \mathrm{B}$ activation. Mol Cell Biol 34: 325-334, 2014

35. Gao M, Wang X, Zhang X, Ha T, Ma H, Liu L, Kalbfleisch JH, Gao X, Kao RL, Williams DL, et al: Attenuation of cardiac dysfunction in polymicrobial sepsis by microRNA-146a is mediated via targeting of IRAK1 and TRAF6 expression. J Immunol 195: 672-682, 2015. 